\title{
Substance P- and Enkephalin-like Immunoreactivities Are Colocalized in Certain Neurons of the Substantia Gelatinosa of the Rat Spinal Cord: An Ultrastructural Double-labeling Study
}

\author{
Alfredo Ribeiro-da-Silva, Erik P. Pioro, and A. Claudio Cuello \\ Department of Pharmacology and Therapeutics, McGill University, Montréal, Québec, Canada H3G 1 Y6
}

The finding that certain cells of the substantia gelantinosa of the rat spinal cord contain both substance P (SP)- and enkephalin (ENK)-like immunoreactive material offers new insights into the mechanisms of action of these peptides in the processing of nociceptive sensory information. The simultaneous detection of these immunoreactivities was obtained in the superficial dorsal horn of the rat spinal cord at the ultrastructural level using monoclonal antibodies. An internally radiolabeled monoclonal antibody (against SP or ENK) was used to recognize one antigenic site, while the other antigenic site was identified by either a bispecific monoclonal antibody (for SP) or a monoclonal antibody (for ENK). The bispecific anti-SP antibody recognized HRP, whereas a secondary bispecific antibody recognized both the IgG of the anti-ENK monoclonal antibody and HRP. In laminae I-III, SP-IIke immunoreactivity (SP-LI) and ENK-like immunoreactivity (ENK-LI) were colocalized in a significant number of axonal varicosities, which contained round or pleomorphic synaptic vesicles. Such double-labeled varicosities, however, were not found to be components of synaptic glomeruli. Most of the immunostained boutons of lamina I were SP-like immunoreactive only. In rats pretreated with colchicine, SP. LI and ENK-LI were colocalized in small perikarya of lamina II and in some lamina I cells. These findings indicate that SP and ENK occur in a significant population of interneurons of the superficial dorsal horn. It is suggested that some of these neurons may correspond to stalked cells and release one or the other substance depending on physiological conditions.

The occurrence of substance P (SP)-like immunoreactivity (SPLI) and enkephalin (ENK)-like immunoreactivity (ENK-LI) in the most superficial laminae of the spinal cord and trigeminal subnucleus caudalis has been widely studied in several animal species (for review, see Ruda et al., 1986; Tohyama and Shio-

Received July 19, 1990; revised Nov. 26, 1990; accepted Nov. 27, 1990.

This research study has been supported with funding from NIH Grant NS26415, by the Medical Research Council (Canada), by the Faculty of Medicine, McGill University, and by Medicorp (Canada). A.R.-S. also acknowledges a grant from the Gulbenkian Foundation, Lisbon, Portugal. We are grateful to Dr. Beatrix M. Kopriwa and Mr. Fernando Evaristo, Department of Anatomy, McGill University, for their assistance in radioautography. Thanks are due especially to Ms. Kathy Hewitt for her technical expertise, Mrs. Diane Plant and Ms. Christina Kuszynski for editorial and secretarial assistance, and Mr. Sylvain Côté and Mr. Alan Forster for their technical and photographic assistance.

Correspondence should be addressed to Dr. A. Claudio Cuello, Department of Pharmacology and Therapeutics, McGill University, 3655 Drummond Street, Montréal, Québec, Canada H3G 1 Y6.

Copyright (C) 1991 Society for Neuroscience $0270-6474 / 91 / 111068-13 \$ 03.00 / 0$ tani, 1986). SP-LI occurs in small-diameter primary sensory fibers (Hökfelt et al., 1975; Cuello et al., 1978) in neurons of the dorsal horn (Ljungdahl et al., 1978; Hunt et al., 1981) and, to a limited extent, in fibers descending from the raphe nuclei (Gilbert et al., 1982; Menétrey and Basbaum, 1987). ENK-LI shares the 2 latter origins with SP-LI but is not present in any significant amount in primary sensory fibers (Hökfelt et al., 1977; Del Fiacco and Cuello, 1980; for review, see Ruda et al., 1986). The ultrastructural localization of SP and ENK immunoreactivities has also been studied by several groups, in the rat (Hunt et al., 1980; Priestley et al., 1982; Bresnaham et al., 1984; Ribeiro-da-Silva et al., 1989), in the cat (Glazer and Basbaum, 1983; Ruda, 1986), and in the monkey (DiFiglia et al., 1982; DeLanerolle and LaMotte, 1983; LaMotte and DeLanerolle, 1983).

The ultrastructural characterization of presumptive ENKergic circuits in the superficial laminae of the dorsal horn is of relevance because opiates are strong candidates for presynaptic interactions. Indeed, it has been shown that there are opiate receptors on primary sensory fibers terminating in the substantia gelatinosa (LaMotte et al., 1976; Atweh and Kuhar, 1977; Ninkovic et al., 1981; Atweh and Kuhar, 1983). Furthermore, the in vitro release of SP from microdissected trigeminal subnucleus caudalis substantia gelatinosa can be inhibited by opiates, an effect that is reversible by naloxone (Jessell and Iversen, 1977). Based on the above evidence, it was postulated that ENK-containing terminals should establish axoaxonic synapses with SP boutons of sensory origin (Jessell and Iversen, 1977). However, there is no convincing morphological evidence for such interaction. ENK endings have only occasionally been seen to be presynaptic to other vesicle-containing profiles (Hunt et al., 1980; Bennett et al., 1982; Glazer and Basbaum, 1983; LaMotte and DeLanerolle, 1983), and previous preliminary double-labeling studies have failed to demonstrate such synaptic relations (Cuello, 1983a,b). Two recent immunofluorescence studies demonstrating a colocalization of SP-LI and ENK-LI in some varicosities of the dorsal horn of the cat (Tashiro et al., 1987) and in cell bodies of the superficial laminae of the dorsal horn of the rat (Senba et al., 1988) have raised the possibility of an alternative explanation for SP/ENK interaction in the dorsal horn.

In view of the relative importance of neurokinin-containing sensory input in the processing of sensory information at the spinal cord level and its postulated modulation by opioid peptides (Jessell and Iversen, 1977; for review, see Cuello, 1987), it is necessary to identify the morphological elements containing SP and ENK, as well as the degree of their coexistence. To 
achieve this we have taken advantage of the unique characteristics of bispecific monoclonal antibodies and internally radiolabeled monoclonal antibodies (Kenigsberg and Cuello, 1987), which allow the resolution of 2 antigenic sites utilizing only monoclonal antibodies of high specificity. Accordingly, we have investigated SP/ENK colocalization at the ultrastructural level in laminae I-III of the rat cervical spinal cord dorsal horn. Our results indicate that SP-LI and ENK-LI are colocalized in a considerable number of axonal varicosities that are located primarily in laminae I and II and are presynaptic to dendrites or cell bodies.

Some of these results have been published in abstract form (Ribeiro-da-Silva and Cuello, 1989).

\section{Materials and Methods}

Control animals. Eight male adult Wistar rats (250-300 gm in weight) were anesthetized with Equithesin $(4 \mathrm{ml} / \mathrm{kg}$, i.p.) and perfused through the left ventricle with $15-20 \mathrm{ml}$ of perfusion buffer (for composition, see Connaughton et al., 1986). This was followed immediately by one of the following fixatives at room temperature: (1) $500 \mathrm{ml}$ of a mixture of $4 \%$ paraformaldehyde, $0.1 \%$ glutaraldehyde, and $15 \%$ of a saturated picric acid solution, in $0.1 \mathrm{M}$ phosphate buffer $\mathrm{pH} 7.4$ (PB), followed by $500 \mathrm{ml}$ of the same mixture without glutaraldehyde; (2) $1000 \mathrm{ml}$ of a mixture of $1 \%$ paraformaldehyde and $1 \%$ glutaraldehyde in $0.1 \mathrm{MPB}$ After perfusion, segments $\mathrm{C} 4-\mathrm{C} 5$ of the spinal cord were excised and further fixed for $1 \mathrm{hr}$ by immersion, at $4^{\circ} \mathrm{C}$ in the same final fixative. The tissue was infiltrated overnight at $4^{\circ} \mathrm{C}$ with $30 \%$ sucrose in $0.1 \mathrm{~m}$ $\mathrm{PB}$, quickly frozen by immersion in liquid nitrogen, thawed in $0.1 \mathrm{M}$ $\mathrm{PB}$ at $25^{\circ} \mathrm{C}$, and cut in $50-\mu \mathrm{m}$-thick transverse sections on a Vibratome. In the case of tissue fixed with $1 \%$ paraformaldehyde $/ 1 \%$ glutaraldehyde, sections were treated for 30 min with $1 \%$ sodium borohydride in PBS and rinsed thoroughly with PBS. The sections were subsequently incubated free floating in the respective primary antibodies at $4^{\circ} \mathrm{C}$ for 16 hr.

Characteristics of monoclonal antibodies. The antibodies used were obtained from spent tissue culture supernatants and included (1) a bispecific anti-SP/anti-horseradish peroxidase antibody, coded P4Cl (Suresh et al., 1986; Ribeiro-da-Silva et al., 1989), obtained from the NC1/34 hybridoma cell line (Cuello et al., 1979); (2) an internally radiolabeled anti-SP antibody ( ${ }^{3} \mathrm{H}-\mathrm{NCl} / 34$; Cuello et al., 1982), also obtained from the NC1/34 cell line (Cuello et al., 1979); (3) an anti-ENK monoclonal antibody, obtained from the NOCl hybridoma cell line (Cuello et al., 1984a); and (4) an internally radiolabeled anti-ENK antibody produced with the NOC1 cell line ( $\left.{ }^{3} \mathrm{H}-\mathrm{NOC1}\right)$, as described earlier (Cuello et al., 1983). Bispecific monoclonal antibodies are the product of hybrid hybridomas and recognize both antigen and marker (Milstein and Cuello, 1983, 1984). Internally radiolabeled monoclonal antibodies are obtained by growing hybridoma cell lines in a medium containing radioactive amino acids, which become integrated into the antibody molecule (Cuello et al., 1982).

Immunocytochemistry. Two antibody cocktails were used for overnight incubation, either (1) P4C1 (undiluted or diluted 1:10 in PBS) with ${ }^{3} \mathrm{H}-\mathrm{NOC} 1$ (diluted $1: 10$ to $1: 30$ ), or (2) ${ }^{3} \mathrm{H}-\mathrm{NC} 1 / 34$ (diluted $1: 10$ ) with NOC1 (1:200). All subsequent incubations in antibody and HRP solutions were performed at room temperature. Tissue sections incubated with the latter mixture of antibodies were rinsed twice in PBS and incubated for $2 \mathrm{hr}$ in undiluted anti-mouse IgG/anti-HRP bispecific antibody supernatant (obtained from hybridoma cell line coded McC10; Kenigsberg and Cuello, 1991). The McC10 antibody does not crossreact with any rat $\mathrm{IgG}$ and therefore does not recognize the $\mathrm{P} 4 \mathrm{Cl}$ antibody. After incubation in the antibodies, all tissue sections were washed in PBS and incubated for $2 \mathrm{hr}$ with $5 \mu \mathrm{g} / \mathrm{ml}$ of HRP (Sigma, type VI). Following 3 washes in PBS, sections were reacted with 3,3'-diaminobenzidine tetrahydrochloride (DAB; Sigma) as described previously (Priestley and Cuello, 1983) if the primary antibody had been $\mathrm{P} 4 \mathrm{Cl}$, or with $\mathrm{DAB}$ in $0.1 \mathrm{M} P B(\mathrm{pH}, 7.4)$ containing cobalt chloride and nickel ammonium sulfate (Adams, 1981) if the developing antibody had been $\mathrm{McC} 10$. After the DAB reaction, sections were rinsed 3 times in buffer and osmicated for $90 \mathrm{~min}$ at $4^{\circ} \mathrm{C}$ in osmium tetroxide in $0.1 \mathrm{M} \mathrm{PB}$, dehydrated in ascending alcohols, and flat embedded in Epon. After polymerization at $55^{\circ} \mathrm{C}$ for $24 \mathrm{hr}$, the sections were examined and photographed with a Leitz light microscope. Selected fields were then reembedded in Epon and cured at $55^{\circ} \mathrm{C}$ for $24 \mathrm{hr}$. The blocks were trimmed to include the middle section of the lateromedial extension of laminae I-III, as described earlier (Ribeiro-da-Silva et al., 1989). For light microscopic radioautography, $1-\mu \mathrm{m}$-thick sections were obtained with an ultramicrotome, collected on glass slides dipped in Kodak NTB-2 nuclear photographic emulsion and developed with Kodak D-170 after 4-40 d of exposure, as described previously (Kopriwa and Leblond, 1962). For electron microscopic radioautography, ultrathin pale golden sections were obtained with a diamond knife, collected on celloidincoated glass slides, carbon coated, and processed with the Ilford L4 emulsion, as described previously (Kopriwa, 1973; Cuello et al., 1983). After exposure for 1-12 months, the radioautograms were developed with Kodak D19b, collected on copper grids, and examined under the electron microscope. Grids were either noncontrasted or contrasted with uranyl acetate alone or with uranyl acetate and lead citrate. The amount of background fog of the radioautogram was negligible. For maximal accuracy at the ultrastructural level, only neuropil profiles overlaid by at least 3 silver grains were considered specifically labeled. In cases where clumps of silver grains were located peripherally in the profile, the possibility of artifactual accumulation of silver grains was excluded by the observation of at least 3 silver grains over the same profile in adjacent sections. Because penetration of the internally radiolabeled and bispecific antibodies in the tissue is excellent (Suresh et al., 1986), the intensity of the immunostaining did not vary significantly throughout the entire thickness of the Vibratome section.

The quantitative data (represented in Fig. 8) were obtained by counting all immunoreactive axonal varicosities for either one or both peptides in 1 ultrathin section per Epon block. Two blocks were used from each of the 4 animals perfused with the higher glutaraldehyde concentration and immunolabeled with the $\mathrm{P} 4 \mathrm{Cl}$ and ${ }^{3} \mathrm{H}-\mathrm{NOCl}$ antibodies. The radioautograms were analyzed after a 6 -month exposure.

Colchicine-treated rats. Five additional rats, as described above, received an injection of colchicine into the cisterna magna ( $80 \mu \mathrm{g} ; 2 \mu \mathrm{g} /$ $\mu \mathrm{l}$ in PBS) $48 \mathrm{hr}$ prior to perfusion. They were perfused with a mixture of paraformaldehyde/glutaraldehyde/picric acid as described in detail elsewhere (Pioro and Cuello, 1988). The spinal cords were infiltrated overnight with $30 \%$ sucrose in $\mathrm{PB}$ as described above and processed following 2 protocols: (1) immunocytochemistry with the $\mathrm{P} 4 \mathrm{Cl}$ and ${ }^{3} \mathrm{H}$ NOC1 antibodies followed by Epon embedding and light microscopic radioautography in $1-\mu \mathrm{m}$-thick sections, as described above; (2) cutting of 3- $\mu$ m-thick serial sections on a Reichert 2800 Frigocut $N$ cryostat. The sections were collected sequentially on each of 4 glass slides, so that slides 1 and 3 were incubated with one antibody sequence and slides 2 and 4 with the other. A peroxidase-antiperoxidase (PAP) protocol (Sternberger, 1979) was used such that the antibodies in sequence 1 were the anti-SP NC1/34 (Cuello et al., 1979; Medicorp, Canada), followed by a rabbit anti-rat IgG (prepared in our laboratory) and a monoclonal rat anti-peroxidase antibody (Cuello et al., 1984b). Antibodies in sequence 2 included the anti-ENK NOC1 (Cuello et al., 1984a; Medicorp, Canada), followed by a rabbit anti-mouse IgG serum (prepared in our laboratory) and a monoclonal mouse anti-peroxidase antibody (Semenenko et al., 1985; Medicorp, Canada).

\section{Results}

\section{Light microscopy}

The distribution of SP-LI and ENK-LI in the dorsal horn of normal control rats has already been described (for review, see Ruda et al., 1986), and our rcsults confirm previous studies. In summary, SP-LI was particularly intense in lamina I and outer lamina II (lamina IIA) but rather diminished in lamina III. ENK-LI was intense in lamina I and particularly in lamina II. The 2 immunoreactivities were easily distinguished in the radioautograms: one (either the SP-LI or the ENK-LI) was represented by the $\mathrm{DAB}$ reaction product, while the other by silver grains in the emulsion which were located in a different focal plane. In all 3 laminae of both control and colchicine-treated rats, silver grains were frequently observed over enzymatic immunoprecipitates representing presumptive axonal varicosities (Fig. 1 $a, b$ ).

Radioautograms from rolchicine-treated rats demonstrated that peptide coexistence occurred also in small nerve cell bodies 

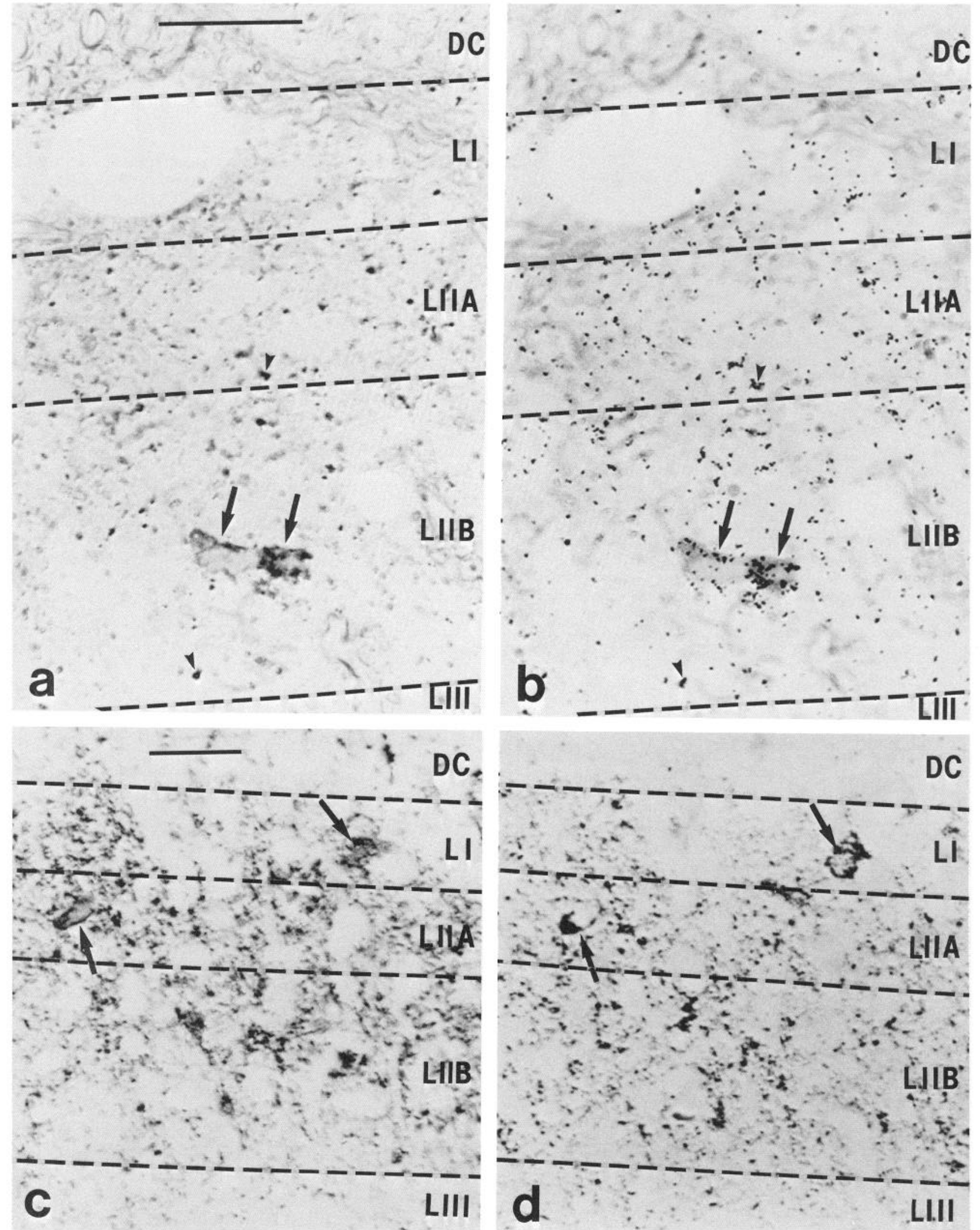

Figure 1. Light microscopy demonstration of SP/ENK colocalization in neurons of the superficial dorsal horn from colchicine-treated rats. $a$ and $b$ represent 2 focal planes in a $1-\mu \mathrm{m}$-thick plastic section from material incubated in a single step with the $\mathrm{P} 4 \mathrm{Cl}$ and ${ }^{3} \mathrm{H}-\mathrm{NOC1}$ antibodies and exposed $15 \mathrm{~d}$ for radioautography. Two cell bodies immunoreactive for SP ( $a$, arrows) located in the middle third of lamina II are shown in $b$ to be overlaid by several silver grains representing ENK antigenic sites. Arrowheads indicate double-labeled presumptive varicosities. $c$ and $d$ represent 2 sequential 3- $\mu \mathrm{m}$-thick cryostat sections incubated, respectively, for the demonstration of SP-LI (c) and ENK-LI (d) using a PAP protocol. Arrows point to double-labeled cells. $D C$, dorsal column; $L I$, lamina I; $L I I A$, lamina IIA; $L I I B$, lamina IIB; $L I I I$, lamina III. Scale bars, $20 \mu \mathrm{m}$. 
of lamina I and especially of lamina II (Fig. 1 $a, b$ ). In lamina II, most of the double-labeled cells were localized in its outer $2 / 3$. This SP/ENK colocalization in neuronal cell bodies was confirmed by the analysis of serial $3-\mu \mathrm{m}$-thick cryostat sections that were incubated alternately for the immunocytochemical demonstration of each of the 2 peptides using a PAP protocol (Fig. $1 c, d)$. The neuronal perikarya, as measured in cryostat sections, had cross-sectional diameters averaging $8 \times 6 \mu \mathrm{m}$ in lamina II and $12 \times 8 \mu \mathrm{m}$ in lamina $\mathrm{I}$.

\section{Electron microscopy}

Two different signals representing either the radioactive $\left({ }^{3} \mathbf{H}\right)$ source or enzymatic (HRP) activity were easily distinguishable and were associated with a variety of neuronal profiles. These immunoreaction signals were found either individually or coexisting in the neuronal profiles. This communication will emphasize the characteristics of elements displaying both (SP/ENK) immunoreactivities simultaneously. An example of boutons revealing exclusively ENK-LI or SP-LI is illustrated in Figure $2 a$, in which the immunoreactive synaptic boutons contact a common dendrite. Of the profiles containing both SP-LI and ENKLI, 35\% displayed a synaptic contact (e.g., see Fig. 2b,c), and $65 \%$ showed no evidence of a synapse (see Fig. $3 a$ ). However, because the synaptic contacts were counted on a single section per Epon block, the actual number of synapses established by the double-labeled profiles may be higher than detected. A detailed study of 180 double-labeled boutons possessing visible synapses identified $85 \%$ as asymmetric and $15 \%$ as symmetric. An asymmetric synapse over a small dendrite is shown in Figure $3 b$, and a symmetric synapse on a medium-sized dendrite is shown in Figure $4 a$.

Most double-labeled varicosities were dome shaped. This type of bouton was observed in all 3 laminae of the superficial dorsal horn, as illustrated in Figures $2 c, 3 a$, and $6 a$. Much less frequent, but present in all 3 laminae, were irregularly shaped boutons that were usually apposed to dendritic profiles. Figure $4 b$ illustrates one such bouton in a rare association with an SP-like immunoreactive dendrite. The dome-shaped boutons were observed making synaptic contacts with dendritic profiles primarily of a small size, though medium- or large-sized dendritcs were also contacted, as seen in laminae I and IIA (Fig. 2b,c). Occasionally, dome-shaped SP/ENK-like immunoreactive profiles surrounded entirely a small dendritic spine (Fig. 2c) or were apposed to a nerve cell body (Fig. $3 c$ ).

The association of peptide-LI with synaptic glomeruli was studied with special attention. It is interesting to note that, in the areas studied, double-labeled axonal profiles were never components of synaptic glomeruli. On the other hand, highly scalloped varicosities possessing only SP-LI were often the central component of synaptic glomeruli (Fig. $5 a$ ). The peripheral axons of synaptic glomeruli were either nonimmunoreactive for either substance or contained only ENK-LI, as shown in Figures $5 c$ and $6 b, c$. Dendrites contacting central glomerular boutons were usually unstained, though some were ENK immunoreactive or double labeled (Fig. $5 b$ ); they rarely possessed SP-LI. Presynaptic dendrites, inside glomeruli or outside, never displayed SP-LI or SP/ENK double-labeling, though some were immunoreactive exclusively for ENK, as illustrated in Figure $4 c$

Results of the quantification of immunolabeled axonal boutons are shown in Figure 7 . The laminar incidence of doublelabeled varicosities varied; in laminae I and IIA, they were slightly more frequent than profiles containing only ENK-LI. Such ENK-like immunoreactive profiles were more numerous in lamina IIB and particularly in lamina III (Fig. 7). Profiles displaying exclusively SP-LI prevailed in all laminae (Fig. 7).

\section{Discussion}

This study provides evidence of axonal varicosities immunolabeled for both SP and ENK in the superficial dorsal horn of the rat spinal cord and, using 2 different protocols, confirms and expands earlier reports of SP-LI and ENK-LI colocalization in nerve cell bodies of laminae I and II (Katoh et al., 1988; Senba et al., 1988). Although the colocalization of SP and ENK immunoreactivities in varicosities of the spinal cord was described previously in the cat using a double-immunofluorescence protocol, such varicosities were reportedly rare in the dorsal horn (Tashiro et al., 1987). In contrast, our ultrastructual results in the rat show double-labeled varicosities to be relatively frequent in laminae I-III, particularly in laminae I and IIA, where they comprise more than $50 \%$ of the varicosities immunolabeled for ENK (see Fig. 7). A previous study (Katoh et al., 1988) described the colocalization of SP-LI and ENK-LI in axons of the rat dorsal horn at the ultrastructural level. However, the freezedrying technique used did not allow any detailed study of the morphology and synaptic rclations of thc doublc-labcled profiles. Therefore, our study provides the first comprehensive description of the morphological features and synaptic relations of double-immunolabeled profiles in the superficial laminae of rat dorsal horn.

The immunocytochemical double-labeling technique used in this ultrastructural study is an improvement on a similar pro-

\footnotetext{
Figure 2. Ultrastructural features of SP/ENK double labeling in lamina I. Unless stated otherwise, these micrographs and those in Figures 3-6 were obtained from animals perfused with $1 \%$ paraformaldehyde/ $1 \%$ glutaraldehyde mixture where the immunoprecipitate corresponds to SP staining (demonstrated with $\mathrm{P} 4 \mathrm{C} 1$ ) and the silver grains represent ENK antigenic sites (recognized radioimmunocytochemically with ${ }^{3} \mathrm{H}-\mathrm{NOC}$ ). All electron micrographs were obtained from radioautograms exposed for 6 months and developed with D19b. $a$, A large dendrite $(D)$ is postsynaptic to profiles that contain only SP-LI (open arrow) or ENK-LI (solid arrow). $b$, A profile colocalizing SP/ENK immunoreactivities (double arrow) is apposed to a medium-sized dendrite $(D)$ establishing an asymmetric contact with it (small arrow). Note also a profile immunolabeled only for SP (open arrow). c, A double-labeled dome-shaped profile (double arrow) establishes an asymmetric contact (small arrows) with a small dendritic spine. Scale bars, $0.5 \mu \mathrm{m}$.
}

Figure 3. Morphology of double-labeled varicosities in laminae I and IIA. a, In lamina IIA, a double-labeled bouton (double arrow) is apposed to a nonlabeled varicosity (asterisk); no obvious synapse is observed. In this figure, SP antigenic sites were detected by radioimmunocytochemistry, and ENK antigenic sites by immunoperoxidase reaction product (as described in Materials and Methods). $b$. A double-labeled small varicosity (double arrow) is presynaptic to a small dendrite $(D)$ at an asymmetric contact (small arrow) in lamina I. $c$, A double-labeled varicosity (double arrow) is presynaptic to both a nerve cell body $(S)$ and a dendritic profile $(D)$ in lamina IIA. Scale bars, $0.5 \mu \mathrm{m}$. 

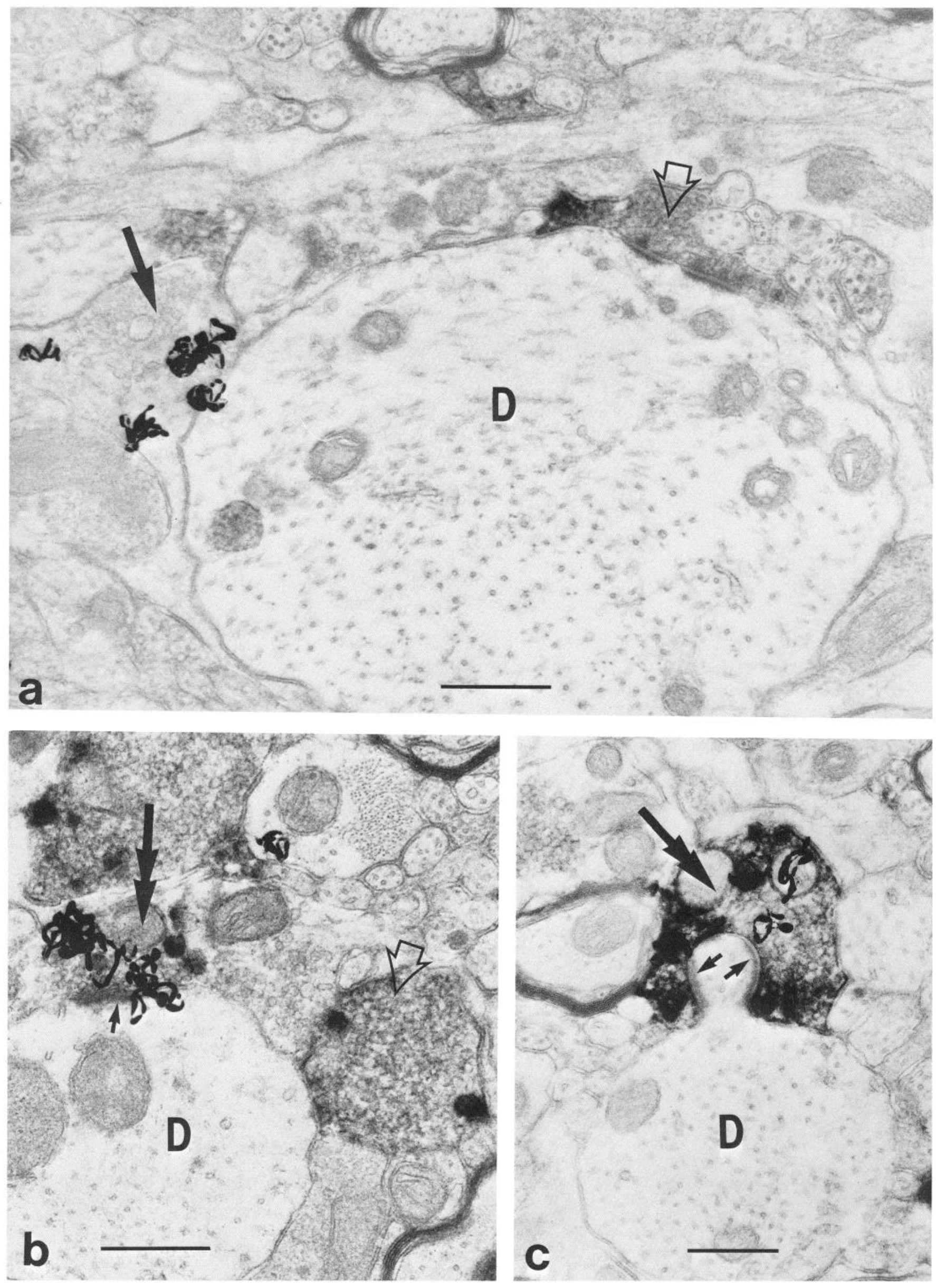


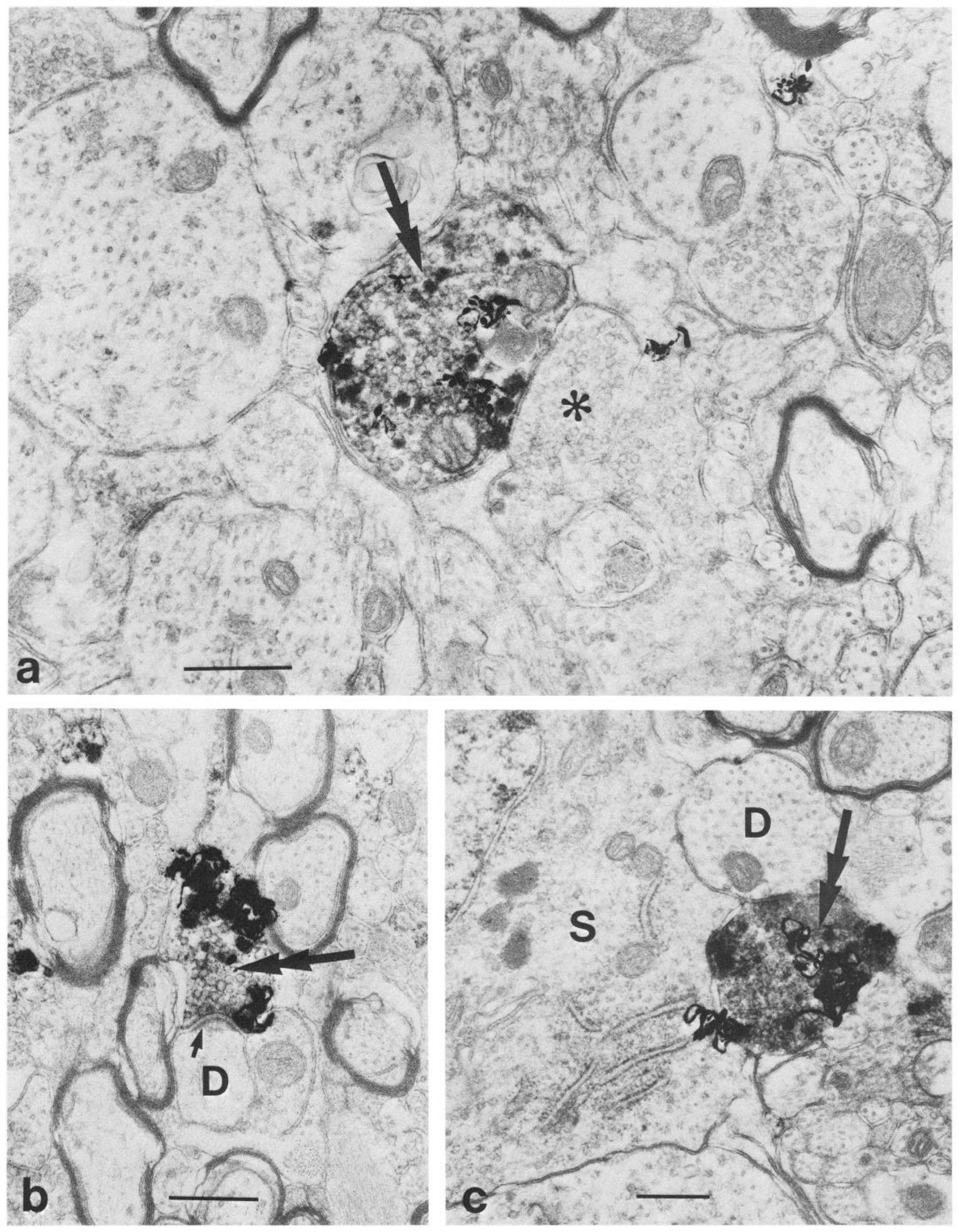



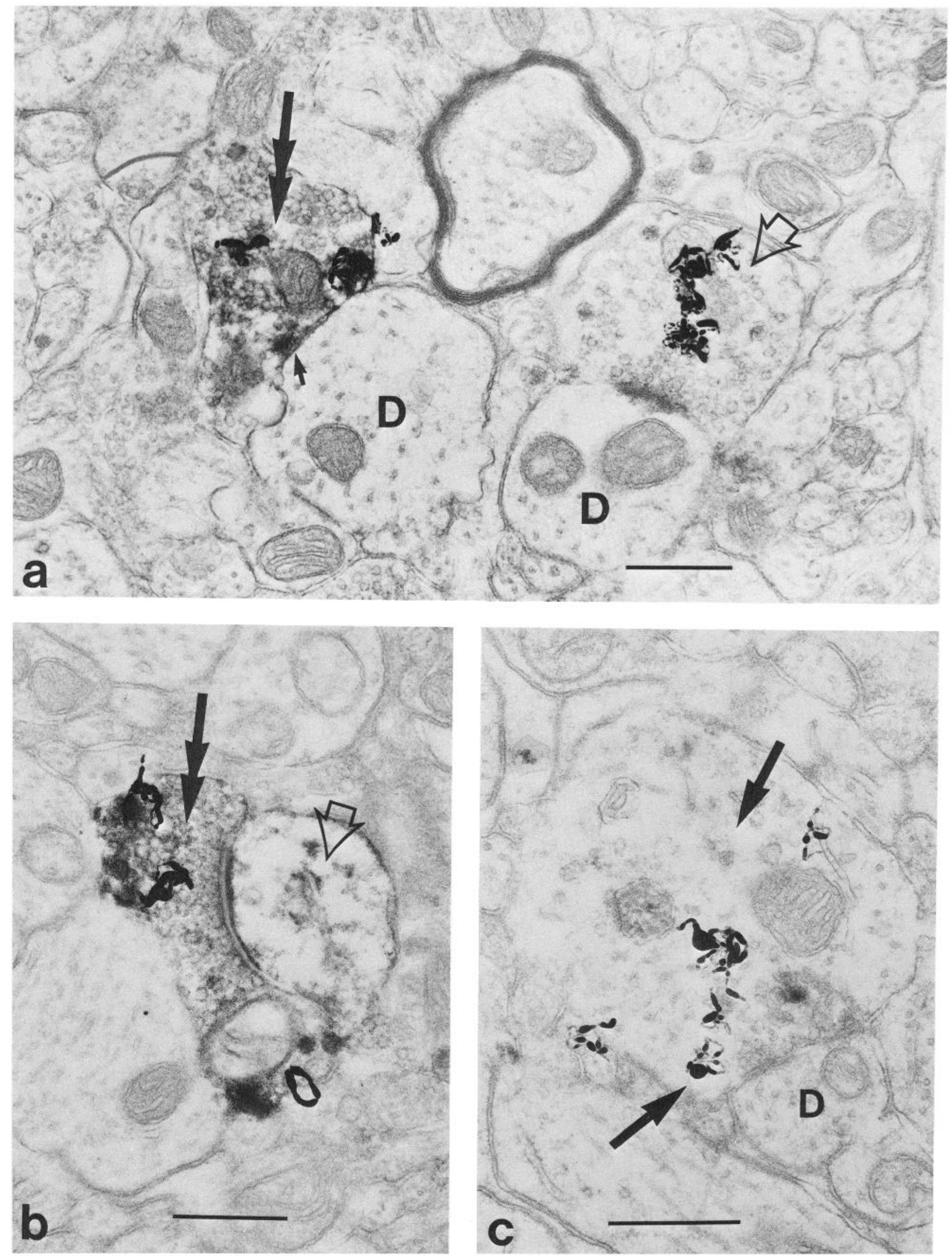

Figure 4. Morphology of double-labeled varicosities in outer lamina II (lamina IIA). $a$, In lamina IIA, a double-labeled varicosity (double arrow) establishes a symmetric contact (small arrow) with a dendrite $(D)$. An SP-only immunolabeled profile (open arrow) is presynaptic to another dendritic profile. In this figure, radioimmunocytochemistry was used for SP sites and immunoperoxidase for ENK sites (as described in Materials and Methods). $b$, A double-labeled varicosity of irregular shape (double arrow) contacts an SP-like immunoreactive dendrite (open arrow) in lamina IIA. $c$, A nonglomerular presynaptic dendrite shows exclusively ENK-LI (arrows) and is presynaptic to a dendrite $(D)$. Scale bars, $0.5 \mu \mathrm{m}$. 
tocol used in a preliminary study of the trigeminal subnucleus caudalis substantia gelatinosa (Cuello et al., 1982; Cuello, 1983a). The use of 2 single molecular probes (the anti-SP bispecific antibody and the radiolabeled anti-ENK antibody) in a simultaneous incubation allowed the 2 antibodies to compete freely for the antigenic sites. Together with the excellent penetration of the tissue by the bispecific antibodies (Suresh et al., 1986), this permitted immunolabeling throughout the entire thickness of the $50-\mu \mathrm{m}$-thick Vibratome section. The latter advantage is particularly germane because a large number of ultrathin sections are usually needed for electron microscope radioautography. Previous limitations of immunocytochemical techniques are probably the reason why SP/ENK colocalization has not been detected earlier. Furthermore, our use of monoclonal antibodies of well-established specificity eliminates the possibility of cross-reactivity with primary sites or developing antibodies. In this respect, it is important to note that the results wcrc consistent whether the internally labeled immunoglobulin was an anti-SP (NC1/34) or anti-ENK (NOC1) antibody. The characteristic pattern of immunolabeled profiles provides further proof of the specificity of the technique. Central varicosities of synaptic glomeruli never contained ENK-LI, though some were immunoreactive for SP. This was to be expected because glomerular central varicosities are thought to represent boutons of primary sensory origin (Ribeiro-da-Silva et al., 1989) and ENKLI has never been demonstrated in spinal ganglia to any significant degree (Garry et al., 1989). The fact that only ENK-like immunoreactive profiles were occasionally seen to represent peripheral axons in glomeruli $\left(\mathrm{V}_{2}\right.$ profiles) demonstrates a consistent identification of a specific subpopulation of immunoreactive profiles.

In their study, Senba et al. (1988) used NC1/34 (Cuello et al., 1979) to detect the SP antigenic sites. Because the anti-SP bispecific antibody used in the present study is derived from the NC1/34 cell line, the SP-like immunoreactive cell bodies detected here and by Senba et al. (1988) must be of the same population. Because the anti-SP antibodies used in both studies are directed against the C terminal of the SP molecule, SP is not distinguished from the other mammalian neurokinins, particularly neurokinin A (NKA) and neurokinin B (NKB; for review, see Helke et al., 1990). This cross-reactivity with NKA does not pose a problem because NKA and SP, but not NKB, are derived from the same precursor (for review, see Helke et al., 1990); consequently, they are colocalized throughout most of the nervous system, including primary sensory neurons (Dalsgaard et al., 1985). Radioimmunoassay studies indicated that $\mathrm{NKB}$ occurred in interneurons and/or projection neurons of the dorsal horn, but even after dorsal root transection, SP occurred in much higher concentrations than NKB (Ogawa et al., 1985).
Furthcrmore, in situ hybridization studies of the rat cervical spinal cord demonstrated that cells containing mRNAs encoding for SP/NKA were frequent in laminae I-II and rare in lamina III, whereas mRNAs encoding for NKB were frequent in lamina III and rare in laminae I-II (Warden and Young, 1988). Because the neurons colocalizing SP and ENK described in this study were rare in lamina III, it is unlikely that this SP-LI represents NKB immunoreactivity. However, we should not exclude the possibility that some of these neurons possessing SP-LI contain NKB rather than SP.

The anti-ENK antibody used in our study was generated from immunizations with Leu-ENK, though it does not distinguish Leu- from Met-ENK and does not recognize dynorphin (Cuello et al., 1984a). On the other hand, the anti-ENK antibody used by Senba et al. (1988) recognizes neither Met- nor Leu-ENK, but rather a precursor of ENK (Met-ENK-Arg ${ }^{8}-\mathrm{Gly}^{7}-\mathrm{Leu}^{8}$, or ENK-8) (Shimosegawa et al., 1987). Despite these apparent differences in antigen recognition, we propose that antibodies in both studies recognize the same ENKergic cell population. In support of this, neither antibody labels dynorphin (derived from preproenkephalin B) or distinguishes between Leu- and MetENK (both derived from preproenkephalin A). However, further studies are required to confirm this hypothesis.

In contrast with SP-LI, ENK-LI has been shown only in a very reduced number of primary sensory neurons (see Ruda et al., 1986; Garry et al., 1989). However, a primary sensory origin for a small number of the varicosities double-labeled for SP-LI and ENK-LI cannot be excluded. Similarly, some of the doublelabeled profiles may originate from axons descending from the raphe nuclei, though SP/EK colocalization has not yet been described in the brain stem and most of the axons of such urigin terminate in the ventral horn (Gilbert et al., 1982; Menétrey and Basbaum, 1987). Therefore, it is probable that most, if not all, the varicosities colocalizing SP-LI and ENK-LI originate from the double-labeled neurons, which can be demonstrated with colchicine treatment (Senba et al., 1988; present results). These cell bodies were small and found primarily in the outer $2 / 3$ of lamina II. Although a quantification of the relative percentages of double-labeled neurons per lamina was not attempted, counts on light microscopic radioautograms from 2 colchicine-treated animals revealed that about $50 \%$ of the neurons with ENK-LI were also immunoreactive for SP. By contrast, almost all SP-immunoreactive neurons were ENK-immunoreactive (A. Ribeiro-da-Silva and A. C. Cuello, unpublished observations). These percentages concur with those obtained by Senba et al. (1988). No presynaptic dendrites were ever double labeled. Rather, a number of double-labeled varicosities were seen terminating presynaptically to large- or medium-sized dendrites of lamina I neurons. In all probability, the neurons colo-

\footnotetext{
Figure 5. Ultrastructural features of immunolabeled profiles in synaptic glomeruli of lamina IIB. The sections were incubated for the demonstration of both SP- and ENK-like immunoreactive sites. $a$, A central varicosity of a type I synaptic glomerulus $\left(C_{l}\right)$ and a nonglomerular scalloped terminal (open arrow) are both immunoreactive for only SP; terminals with these morphological characteristics are consistent with a primary sensory origin (see Ribeiro-da-Silva et al., 1989). $b$, A double-labeled (double arrow) dendrite in a type I synaptic glomerulus. $c$, A peripheral axonal varicosity (arrow) of a type II glomerulus is only immunoreactive for ENK; $C_{I I}$, central varicosity of a type II glomerulus. Scale bars, $0.5 \mu \mathrm{m}$.
}

Fixure 6. Features of immunolabeling in lamina III. $a$, A double-labeled dome-shaped bouton (double arrow) is presynaptic to a small dendrite $(D)$. Observe also the central bouton of a type II glomerulus $\left(C_{H}\right)$, which is contacted by a presynaptic dendrite probably single-labeled for ENK (arrow). $b$ and $c$, Peripheral axons in glomeruli immunolabeled for only ENK (arrows) in material incubated in a cocktail of bispecific P4Cl and radiolabeled NOC1 (silver grains in $b$ ) or of radiolabeled NC1/34 and $\mathrm{NOC1} / \mathrm{McCl} 10$ (immunoprecipitate in $c$ ). Scale bars, $0.5 \mu \mathrm{m}$. 

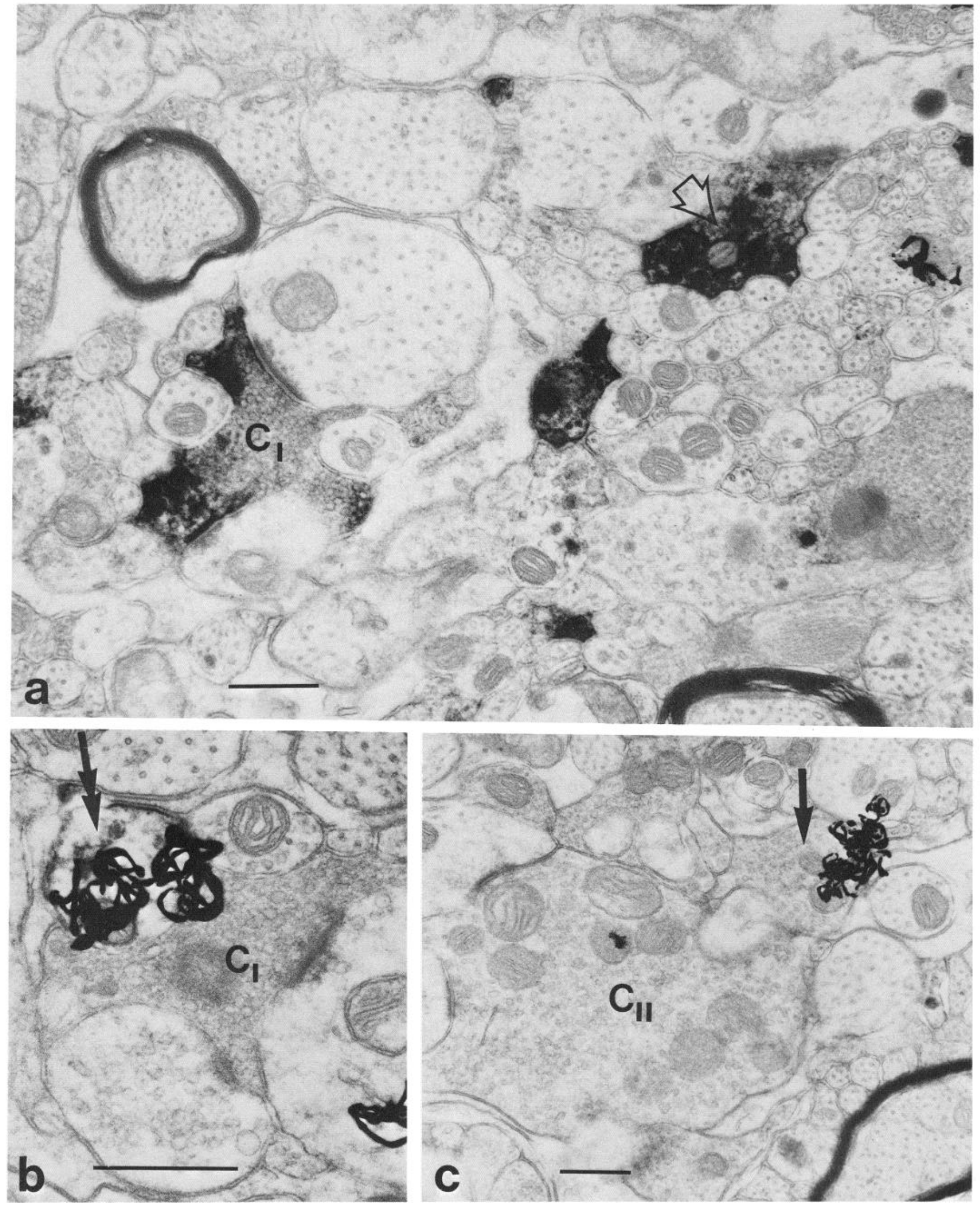

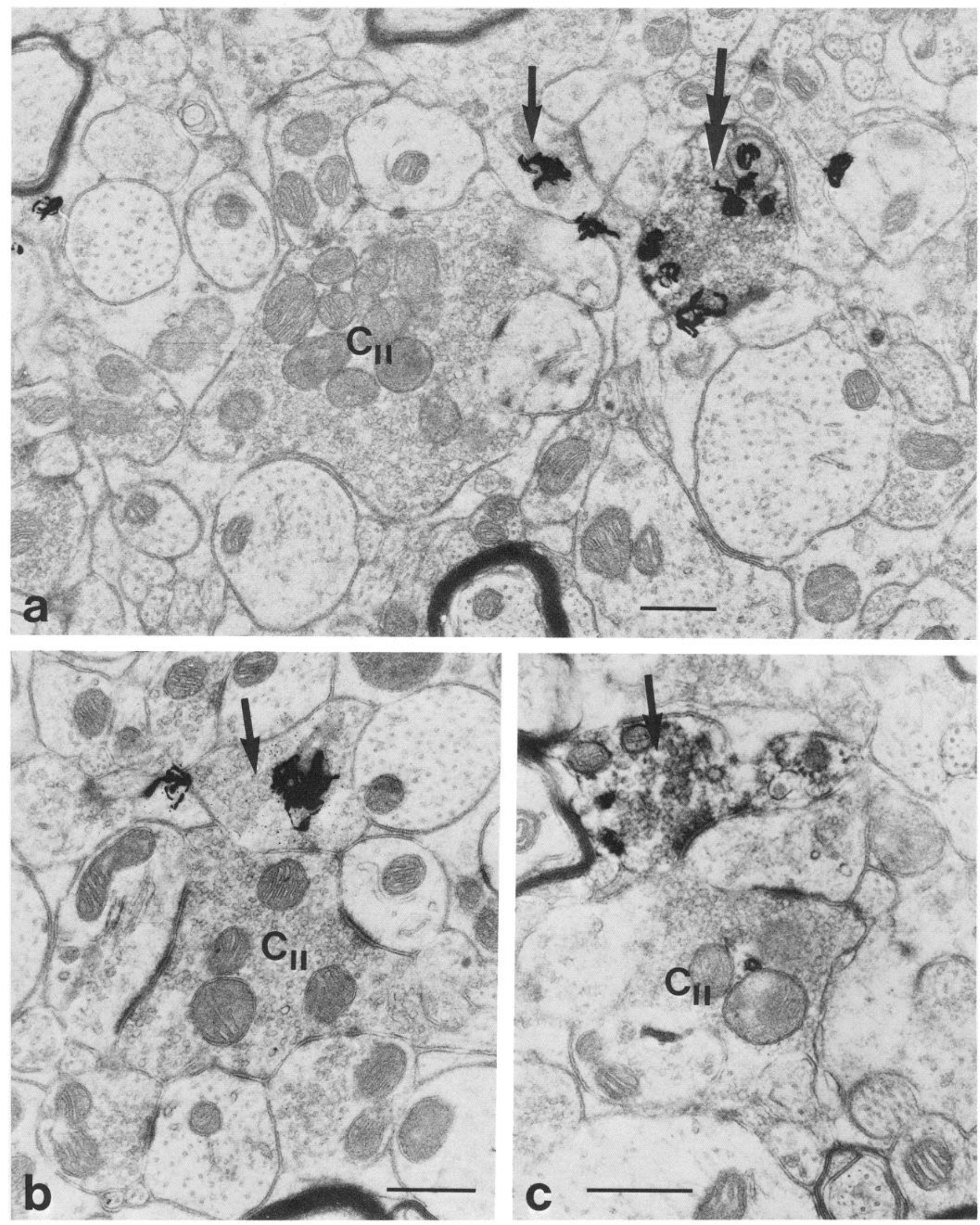
PEPTIDE CO-LOCALIZATION IN AXONAL BOUTONS OF LAMINAE I-III

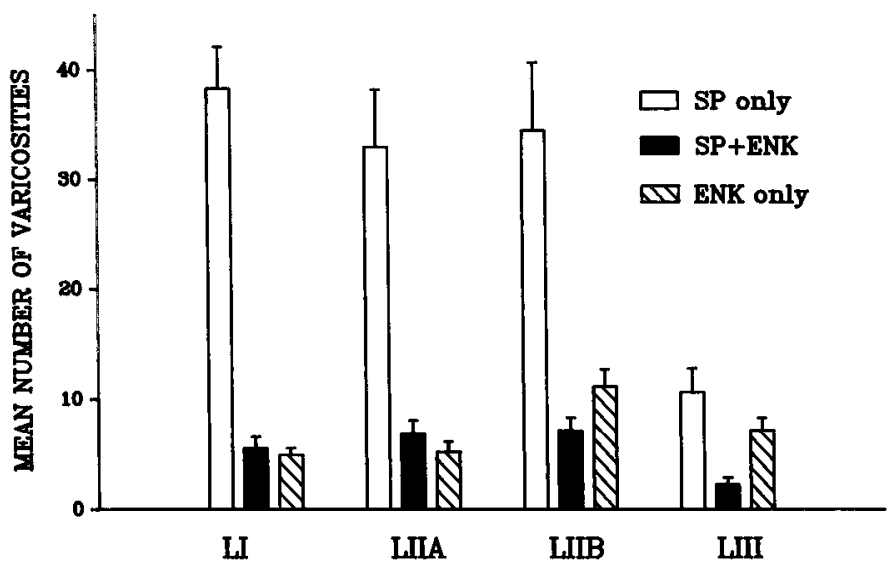

calizing SP-LI and ENK-LI correspond to more than 1 cell type (see below). However, our findings suggest that some of the double-labeled neurons may correspond to stalked cells because, according to Gobel and collaborators, in the cat these neurons lack presynaptic dendrites and have axons terminating in lamina I (Bennett et al., 1980; Gobel et al., 1980). Furthermore, stalked cells in the same animal species were shown to be immunoreactive for ENK (Bennett et al., 1982). Because stalked cells are considered to be excitatory interneurons that relay primary

Figure 7. Mean numbers of immunolabeled varicosities per sample and per lamina $( \pm$ SEM). Quantitative data were obtained by counting all immunoreactive axonal varicosities in 1 ultrathin section per Fpon block. Two blocks per rat from a total of 4 animals, perfused with the higher glutaraldehyde concentration, were immunolabeled with the $\mathrm{P} 4 \mathrm{Cl}$ (bispecific) and the ${ }^{3} \mathrm{H}-\mathrm{NOCl}$ antibodies. The radioautographs were exposed for 6 months. Total number of varicosities counted, 1331.

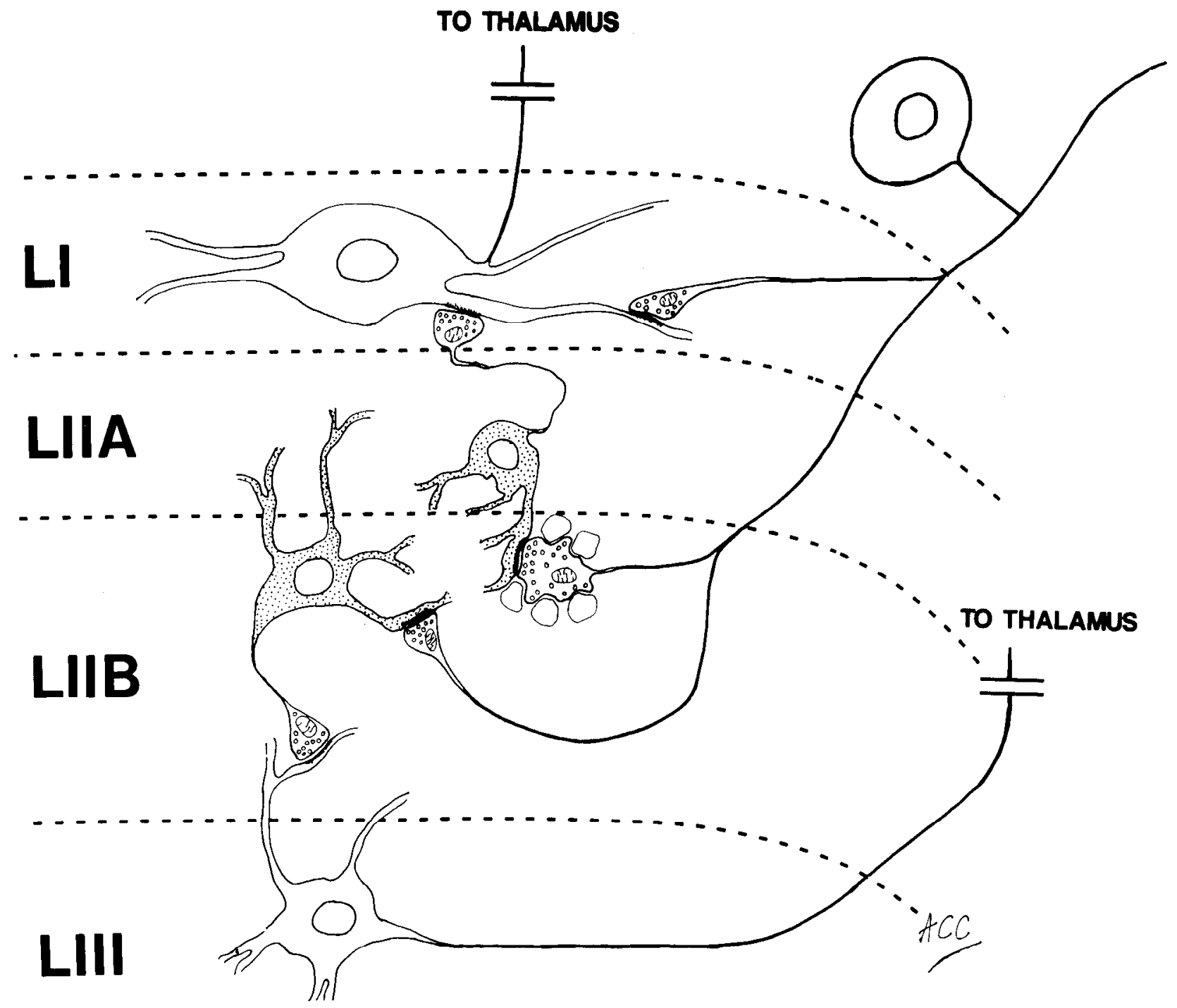

Figure 8. Diagrammatic representation of possible synaptic connections of neurons double-labeled for SP and ENK (stippled) in the superficial dorsal horn, as described in Discussion. Represented also are nociceptive primary sensory fibers and boutons. Thalamus-projecting neurons are represented in laminae I and III, with dendrites of cell in the latter location located in lamina IIB. The double-labeled cell shown in lamina IIB represents an interneuron of the main sensory pathway that receives a synapse from a primary sensory fiber and contacts a spinothalamic neuron of the deeper dorsal horn with its axon. The projection neuron of the deeper dorsal horn (here represented in lamina III) would thereby not receive 
sensory information to lamina I projection neurons (Bennett et al., 1979), that they contain opiate immunoreactivity appears paradoxical. However, our immunocytochemical findings of ENK, a characteristically inhibitory neuropeptide (Duggan et al., 1977; for review, see North and Williams, 1983), colocalized with SP, which is usually excitatory (Henry, 1976; for review, see Nicoll et al., 1980; Otsuka and Yanagisawa, 1987) in presumptive stalked cells, reconciles earlier observations. It is likely that stalked cells are not the only dorsal horn neurons immunoreactive for both peptides because we detected double-labeled cells in lamina I and in the inner third of lamina II. A detailed morphological characterization of such double-labeled neurons is therefore required.

At present, it can be speculated that the double-labeled cells are interneurons within the main sensory pathway receiving primary sensory input (likely nociceptive) and transmitting it to projection neurons. These possible relationships are schematically represented in Figure 8. Alternatively, some or all of the double-labeled cells may be interneurons not within the main sensory pathway but parallel to it (Fig. 8).

Accordingly, in agreement with previous findings (Cuello, 1983a,b), we have not found any evidence of presynaptic contacts of ENK-like immunoreactive profiles on those containing SP-LI. Neither did we frequently observe varicosities that contained only SP-LI sharing a common postsynaptic target with an ENK-like immunorcactive profilc. Furthermorc, we found that most ENK-like immunoreactive profiles in lamina I and outer lamina II were also immunoreactive for SP. The type of synaptic contacts established by these varicosities and the localization of many double-labeled perikarya, as revealed after colchicine treatment, suggest that many of these neurons are stalked cells that could regulate their own excitation by means of ENK release (affecting either autoreceplors or postsynaptic mechanisms). Although it is not possible to define a precise role for the peptides, because they are costored and presumably coreleased from these interneurons, we can speculate that they participate in the fine regulation of synaptic sites. Thus, an excitatory response elicited by SP (or less likely NKB) could be terminated at pre- or postsynaptic levels by ENK. The possibility of presynaptic control via autoreceptors has been advanced by Ueda et al. $(1986,1987)$. Further research is needed to establish morc preciscly the physiological role for SP/ENKcontaining neurons in the spinal cord dorsal horn, particularly in the modulation of nociception.

\section{References}

Adams JC (1981) Heavy metal intensification of DAB-based HRP reaction product. Histochem Cytochem 29:775.

Atweh SE, Kuhar MJ (1977) Autoradiographic localisation of opiate receptors in rat brain. I. Spinal cord and lower medulla. Brain Res 124:53-67.

Atweh SF, Kuhar MJ (1983) Distribution and function of opioid peptides. Br Med Bull 39:52-74.

Bennett GJ, Hayashi H, Abdelmoumene M, Dubner R (1979) Physiological properties of stalked cells of the substantia gelatinosa intracellularly stained with horseradish peroxidase. Brain Res 164:285289.
Bennett GJ, Abdelmoumene M, Hayashi H, Dubner R (1980) Physiology and morphology of substantia gelatinosa neurons intracellularly stained with horseradish peroxidase. J Comp Neurol 194:809827.

Bennett GJ, Ruda MA, Gobel S (1982) Enkephalin immunoreactive stalked cells and lamina IIb islet cells in cat substantia gelatinosa. Brain Res 240:162-166.

Bresnahan JC, Ho RH, Beattie MS (1984) A comparison of the ultrastructure of substance $P$ and enkephalin-immunoreactive elements in the nucleus of the dorsal lateral funiculus and laminae I and II of the rat spinal cord. J Comp Neurol 229:497-511.

Connaughton M, Pricstley JV, Sofroniew MV, Eckenstein F, Cuello AC (1986) Inputs to motoneurones in the hypoglossal nucleus of the rat: light and electron microscopic immunocytochemistry for choline acetyltransferase, substance $\mathbf{P}$ and enkephalins using monoclonal antibodies. Neuroscience 17:205-224.

Cuello AC (1983a) Central distribution of opioid peptides. Br Med Bull 39:11-16.

Cuello AC (1983b) Non-classical neuronal communications. Fed Proc 42:2912-2922.

Cuello AC (1987) Peptides as neuromodulators in primary sensory neurons. Neuropharmacology 26:971-979.

Cuello AC, Del Fiacco M, Paxinos G (1978) The central and peripheral ends of the substance $\mathbf{P}$ containing sensory neurones in the rat trigeminal system. Brain Res 149:413-429.

Cucllo AC, Galfre G, Milstein C (1979) Detection of substance P in the central nervous system by a monoclonal antibody. Proc Natl Acad Sci USA 76:3532-3536.

Cuello AC, Priestley JV, Milstein C (1982) Immunocytochemistry with internally labelled monoclonal antibodies. Proc Natl Acad Sci USA 79:665-669.

Cuello AC, Galfre G, Milstein C (1983) Preparation and application of monoclonal antibodies for immunohistochemistry and immunocytochemistry. In: Immunohistochemistry (Cuello AC, ed), pp 215256. Chichester: Wiley.

Cuello AC, Milstein C, Couture R, Wright B, Priestley JV, Jarvis J (1984a) Characterization and immunocytochemical application of monoclonal antibodies against enkephalins. J Histochem Cytochem 32:947-957.

Cucllo AC, Milstein C, Wright B, Bramwell S, Priestley JV, Jarvis J (1984b) Development and application of a monoclonal peroxidase antiperoxidase (PAP) immunocytochemical reagent. Histochemistry 80:257-261.

Dalsgaard C-J, Haergerstrand A, Theodorsson-Norheim E, Brodin E, Hökfelt T (1985) Neurokinin A-like immunoreactivity in rat primary sensory neurons; coexistence with substance $P$. Histochemistry 83:37-39.

DeLanerolle NC, LaMotte CC (1983) Ultrastructure of chemically defined neuron systems in the dorsal horn of the monkey. I. Substance P immunoreactivity. Brain Res 274:31-49.

Del Fiacco M, Cuello AC (1980) Substance P and enkephalin-containing neurones in the rat trigeminal system. Neuroscience 5:803815.

DiFiglia M, Aronin N, Lceman SE (1982) Light microscopic and ultrastructural localization of immunoreactive substance $P$ in the dorsal horn of the monkey spinal cord. Neuroscience 7:1127-1139.

Duggan AW, Hall JC, Headly PM (1977) Enkephalins and dorsal hom neurones of the cat: effects on responses to noxious and innocuous skin stimuli. Br J Pharmacol 61:399-408.

Garry MG, Miller KE, Seybold VS (1989) Lumbar dorsal root ganglia of the cat: a quantitative study of peptide immunoreactivity and cell size. J Comp Neurol 284:36-47.

Gilbert RFT, Emson PC, Hunt SP, Bennett GW, Marsden CA, Sandberg BEB, Steinbusch HWM, Verhofstad AAJ (1982) The effects of monoamine neurotoxins on peptides in the rat spinal cord. Neuroscience 7:68-87.

Glazer EJ, Basbaum AI (1983) Opioid neurons and pain modulation:

nociceptive input directly from primary sensory fibers. The cell in lamina IIA receives a synapse from a primary afferent fiber at a synaptic glomerulus, while its axon contacts a lamina I projection neuron. The latter neuron may also receive primary sensory input directly from a primary afferent fiber. The double-labeled neuron in lamina IIA, therefore, would be part of a modulatory sensory pathway, converging with that of the main sensory input. 
an ultrastructural analysis of enkephalin in the cat superficial dorsal horn. Neuroscience 10:357-376.

Gobel S, Falls WM, Bennett GJ, Abdelmoumene M, Hayashi H, Humphrey E (1980) An EM analysis of the synaptic connections of horseradish peroxidase-filled stalked cells and islet cells in the substantia gelatinosa of the adult cat spinal cord. J Comp Neurol 194:781-807.

IIelke CJ, Krause JE, Manthy PW, Couture R, Bannon MJ (1990) Diversity in tachykinin peptidergic neurons: multiple peptides, receptors and regulatory mechanisms. FASEB J 4:1606-1615.

Henry JL (1976) Effects of substance P on functionally identified units in cat spinal cord. Brain Res 114:439-452.

Hökfelt T, Kellerth JO, Nilsson G, Pernow B (1975) Substance P: localization in the central nervous system and in some primary sensory neurons. Science 190:889-890.

Hökfelt T, Ljungdahl A, Terenius L, Elde R, Nilsson G (1977) Immunohistochemical analysis of peptide pathways possibly related to pain and analgesia: enkephalin and substance P. Proc Natl Acad Sci USA 74:3081-3085.

Hunt SP, Kelly JS, Emson PC (1980) The electron microscopic localisation of methionine-enkephalin within the superficial layers (I and II) of the spinal cord. Neuroscience 5:1871-1890.

Hunt SP, Kelly JS, Emson PC, Kimmel JR, Miller RJ, Wu J-Y (1981) An immunohistochemical study of neuronal populations containing neuropeptides or gamma-aminobutyrate within the superficial layers of the rat dorsal horn. Neuroscience 6:1883-1898.

Jessell TM, Iversen LL (1977) Opiate analgesics inhibit substance $P$ release from rat trigeminal nucleus. Nature 268:549-551.

Katoh S, Hisano S, Kawano H, Kagotani Y, Daikoku S (1988) Lightand electron-microscopic evidence of costoring of immunoreactive enkephalins and substance $P$ in dorsal horn neurons of rat. Cell Tissue Res 253:297-303.

Kenigsberg RL, Cuello AC (1987) Role.of immunology in defining transmitter-specific neurons. Immunol Rev 100:279-306.

Kenigsberg RL, Cuello AC (1991) Production of a bi-specific monoclonal antibody recognizing mouse kappa light chains and horseradish peroxidase. Applications in immunoassays. Histochemistry, in press.

Kopriwa BM (1973) A reliable, standardized method for ultrastructural electron microscopic radioautography. Histochemistry 37:1-17.

Kopriwa BM, Leblond CP (1962) Improvements in the coating technique of radioautography. J Histochem Cytochem 10:269-284.

LaMotte C, DeLanerolle NC (1983) Ultrastructure of chemically defined neuron systems in the dorsal horn of the monkey. II. Methionine-enkephalin immunoreactivity. Brain Res 274:51-63.

LaMotte C, Pert CB, Snyder SH (1976) Opiate receptor binding in primate spinal cord: distribution and changes after dorsal root section. Brain Res 112:407-412.

Ljungdahl A, Hökfelt T, Nilsson G (1978) Distribution of substance $P$-like immunoreactivity in the central nervous system of the rat-I. Cell bodies and nerve terminals. Neuroscience 3:861-943.

Menétrey D, Basbaum AI (1987) The distribution of substance P-, enkephalin- and dynorphin-immunoreactive neurons in the medulla of the rat and their contribution to bulbospinal pathways. Neuroscience 23:173-187.

Milstein C, Cuello AC (1983) Hybrid hybridomas and their use in immunohistochemistry. Nature 305:537-540.

Milstein C, Cuello AC (1984) Hybrid hybridomas and the production of hi-specific monoclonal antibodies. Immunol Today 5:299-304.

Nicoll RA, Schenker C, Leeman SE (1980) Substance P as a transmitter candidate. Annu Rev Neurosci 3:227-268.

Ninkovic M, Hunt SP, Kelly JS (1981) Effects of dorsal rhizotomy on the autoradiographic distribution of opiate and neurotensin receptors and neurotensin-like immunoreactivity within the rat spinal cord. Brain Res 230:111-119.

North RA, Williams JT (1983) How do opiates inhibit neurotransmitter release? Trends Pharmacol Sci 4:337-339.
Ogawa T, Kanazawa I, Kimura S (1985) Regional distribution of substance $P$, neurokinin $A$ and neurokinin $B$ in rat spinal cord, nerve roots and dorsal root ganglia, and the effects of dorsal root section and spinal transection. Brain Res 359:152-157.

Otsuka M, Yanagisawa M (1987) Does substance $P$ act as a pain transmitter? Trends Pharmacol Sci 8:506-510.

Pioro EP, Cuello AC (1988) Purkinje cells of adult rat cerebellum express nerve growth factor receptor immunoreactivity: light microscopic observations. Brain Res 455:182-186.

Priestley JV, Cuello AC (1983) Electron microscopic immunocytochemistry for CNS transmitters and transmitter markers. In: Immunohistochemistry (Cuello AC, ed), pp 273-322. Chichester: Wiley.

Priestley JV, Somogyi P, Cuello AC (1982) Immunocytochemical localization of substance $P$ in the spinal trigeminal nucleus of the rat: a light and electron microscopic study. J Comp Neurol 211:31-49.

Ribeiro-da-Silva A, Cuello AC (1989) Substance P and enkephalinlike immunoreactivities coexist in neurons of the rat substantia gelatinosa. An ultrastructural double-labelling study. Eur J Neurosci [Supp] 2:114.

Ribeiro-da-Silva A, Tagari P, Cuello AC (1989) Morphological characterization of substance P-like immunoreactive synaptic glomeruli in the superficial dorsal horn of the rat spinal cord and trigeminal subnucleus caudalis. A quantitative study. J Comp Neurol 281:497515.

Ruda MA (1986) The pattern and place of nociceptive modulation in the dorsal horn. A discussion of the anatomically characterized neural circuitry of enkephalin, serotonin, and substance P. In: Spinal afferent processing (Yaksh TL, ed), pp 141-164. New York: Plenum.

Ruda MA, Bennett GJ, Dubner R (1986) Neurochemistry and neural circuitry in the dorsal horn. Prog Brain Res 66:219-268.

Semenenko FM, Bramwell S, Sidebottom E, Cuello AC (1985) Development of a mouse antiperoxidase secreting hybridoma for use in the production of a mouse PAP complex for immunocytochemistry and as a parent cell line in the development of hybrid hybridomas. Histochemistry 83:405-408.

Senba E, Yanaihara C, Yanaihara N, Tohyama M (1988) Co-localization of substance $\mathbf{P}$ and Met-enkephalin-Arg ${ }^{6}-\mathrm{Gly}^{7}-\mathrm{Leu}^{8}$ in the intraspinal interneurons of the rat, with special reference to the neurons of the substantia gelatinosa. Brain Res 453:110-116.

Shimosegawa T, Koizumi K, Toyota T, Goto Y, Yanaihara C, Yanaihara $N$ (1987) An immunohistochemical study of methionine-enkephalin-Arg ${ }^{6}-\mathrm{Gly}^{7}-\mathrm{Leu}^{8}$-like immunoreactivity-containing neurons in the parasympathetic preganglionic regions of the rat spinal cord. Brain Res 406:341-347.

Sternberger LA (1979) Immunocytochemistry. New York: Wiley.

Suresh MR, Cuello AC, Milstein C (1986) Advantages of bispecific hybridomas in one-step immunocytochemistry and immunoassays. Proc Natl Acad Sci USA 83:7989-7993.

Tashiro T, Takahashi O, Satoda T, Matsushima R, Mizuno N (1987) Immunohistochemical demonstration of coexistence of enkephalinand substance P-like immunoreactivities in axonal components in the lumbar segments of cat spinal cord. Brain Kes 424:391-395.

Tohyama M, Shiotani Y (1986) Neuropeptides in spinal cord. Prog Brain Res 66:177-218.

Ueda H, Fukushima N, Kitao T, Ge M, Tagaki H (1986) Low doses of naloxone produce analgesia in the rat brain by blocking presynaptic autoinhibition of enkephalin release. Neurosci Lett 65:247-252.

Ueda H, Fukushima N, Ge M, Tagaki H, Satoh M (1987) Presynaptic opioid kappa-receptor and regulation of the release of Met-enkephalin in the rat brainstem. Neurosci Lett 81:309-313.

Warden MK, Young WS (1988) Distribution of cells containing mRNAs encoding substance $\mathrm{P}$ and neurokinin $\mathrm{B}$ in the rat central nervous system. J Comp Neurol 272:90-113. 